\title{
Assessment of Drought Resistance in Pearl Millet [Pennisetum americanum (L.) Leeke]. I Factors Affecting Yields under Stress
}

\author{
F. R. Bidinger, V. Mahalakshmi and G. D. P. Rao \\ Pearl Miliet Improvement Program, \\ International Crops Research Institute \\ for the Semi-Arid Tropics (ICRISAT), Patancheru, P.O., Andhra Pradesh 502 324, India.
}

\section{Abstract}

Yield trials of advanced lines of pearl millet were grown under midseason (panicle initiation to flowering) and terminal (flowering to maturity) drought stresses in the dry seasons of 1981, 1982, and 1983. Grain yield and its components were severely reduced by the terminal stress, but were little affected by the midseason drought, as there was compensation by later tillers for yield lost on the earlier shoots.

The major factor determining grain yield of a genotype in both stress treatments was its time to flowering. Because of this, yield-yield component relationships under stress were a result of yield component-phenology relationships. Yield potential (measured in an irrigated treatment in the same field) was generally positively related to yield under stress, but accounted for a much smaller fraction of yield variation than time to fowering. These two factors together accounted for more than $50 \%$ of the total variation in grain yield under stress, suggesting that genotype drought response (drought resistance/susceptibility) was a secondary rather than a primary factor in differences in yield under stress among the genotypes tested.

\section{Introduction}

Breeding major food crops for stable yields in drought stress environments has become a subject of major interest in the past decade (Blum 1979; Simpson 1981; IRRI 1982; Quisenberry 1982). Much of this interest has taken the form of discussion of philosophy, including breeding for specific adaptation to target environments (Hurd 1969, 1974), breeding for broad adaptation or yield stability across the range of variation in the environment (Fischer et al. 1982), and finally breeding for drought resistance based on specific morphological or physiological characters (Blum 1979; Quisenberry 1982; Richards 1982). Blum (1979) argued for the third approach by analogy with disease resistance, suggesting that both the strategy of disease resistance breeding (incorporation of independent resistance characters into high-yielding, adapted cultivars), and the methodology (identification of sources, crossing, and screening of progeny) are appropriate to drought resistance breeding. This approach requires the identification of simple morphological or physiological traits which confer an advantage under one or more specific stress conditions, and the demonstration of their contribution to crop yield in such conditions.

Hypotheses concerning specific plant characteristics which may be associated with drought resistance can be developed either through analysis of the specific nature of the stress itself, and its effects on plant growth, or through analysis of the performance of sets of genotypes in such stress situations. These two 
alternatives have been termed by Fischer (1981) as the ideotype strategy and the black box approach. We believe that the black box approach is a very useful initial step in a breeding program for drought resistance because: (1) it permits analysis of the relative importance of yield potential and drought escape as factors in yields achieved in stress (Fischer and Maurer 1978), two factors which may account for as much as half of the variation in grain yield in stress situations (Bidinger et al. 1982); (2) it allows a direct estimate of the drought resistance or susceptibility of individual genotypes, which provides a basis for correlation analyses to evaluate the usefulness under stress of a wide range of individual plant characters (Fischer and Wood 1979); and (3), as these studies are most logically carried out on materials from the breeder's gene pool, results can be used immediately in a resistancebreeding program.

This and the subsequent paper of this series illustrate the use of such a black box analysis based on data from three years of advanced field trials of pearl millet [Pennisetum americanum (L.) Leeke] grown under drought stress conditions. The objective of the first paper was to understand the reasons for differences among genotypes in grain yield under drought stress conditions using mainly correlation analyses of grain yield and readily measurable developmental and morphological traits. The second paper presents a method for analysis of individual cultivar response to stress, based on the understanding of the factors affecting yield under stress developed in the first paper. Although the data presented pertain to millet, the methods presented are applicable to other crops as well.

\section{Materials and Methods}

\section{Genetic Material}

The materials grown each year were the three advanced breeding trials of the Pearl Millet Breeding Program, a total of 72 entries divided equally among F1 hybrids, synthetic varieties, and population varieties derived from composites. Nearly all entries changed from year to year, as they were either dropped from the trials or promoted to the next level of testing. This eliminated the possibility of acrossyear comparisons, but this was not considered a major drawback, as the objective of these experiments was to evaluate the effects of drought stress on currently superior entries rather than on specific entries.

\section{Drought Treatments}

The trials were grown under irrigation during the dry season (January-May), which is almost rain free and has high mean air temperatures and large vapour pressure deficits which resulted in high potential evaporation rates (Fig. $1 a-1 c$ ). Night temperatures early in this season were cooler than would be experienced in a normal (rainy) season, which resulted in slower early growth and development. This effect, however, was offset by the higher levels of radiation and shorter days of this season which favored higher rates of crop growth and earlier flowering, respectively. Although temperatures and potential evaporation rates were quite high by the end of the dry season, they did not exceed those during drought periods in north-west India, where the majority of pearl millet in the subcontinent is grown.

Irrigation was manipulated to create three different moisture regimes: a fully irrigated control treatment, a midseason stress treatment where the crop was under progressive stress from approximately foral initiation (20 days after emergence [DAE]) to flowering (about 50 DAE) and rewatered thereafter until maturity, and a terminal stress where irrigation was terminated at flowering. The first of these treatments was used to measure non-stressed crop characteristics, the second to evaluate ability to recover from a severe drought during the normal period of canopy development and panicle growth, and the third to measure the ability to set and fill grains under a simulated early ending of the rains. The actual timings of the stress are indicated in Fig. 1, relative to the range in time to flowering for all genotypes in the trials. The use of midseason and terminal stress treatments was based on previous experience which indicated that genotype response could differ markedly with pre- and post-flowering stress. Very little information is available on the actual probabilities of occurrence of stress at different 
times in millet-growing areas, and the timing used in these experiments should not necessarily be considered representative of stress pattern of these zones. The soil was a sandy loam (Alfisol) of about $60 \mathrm{~cm}$ depth, making the soil unable to support a full crop canopy without stress for more than 7-10 days under the evaporation rates in the dry season (Fig. 1a-1c).

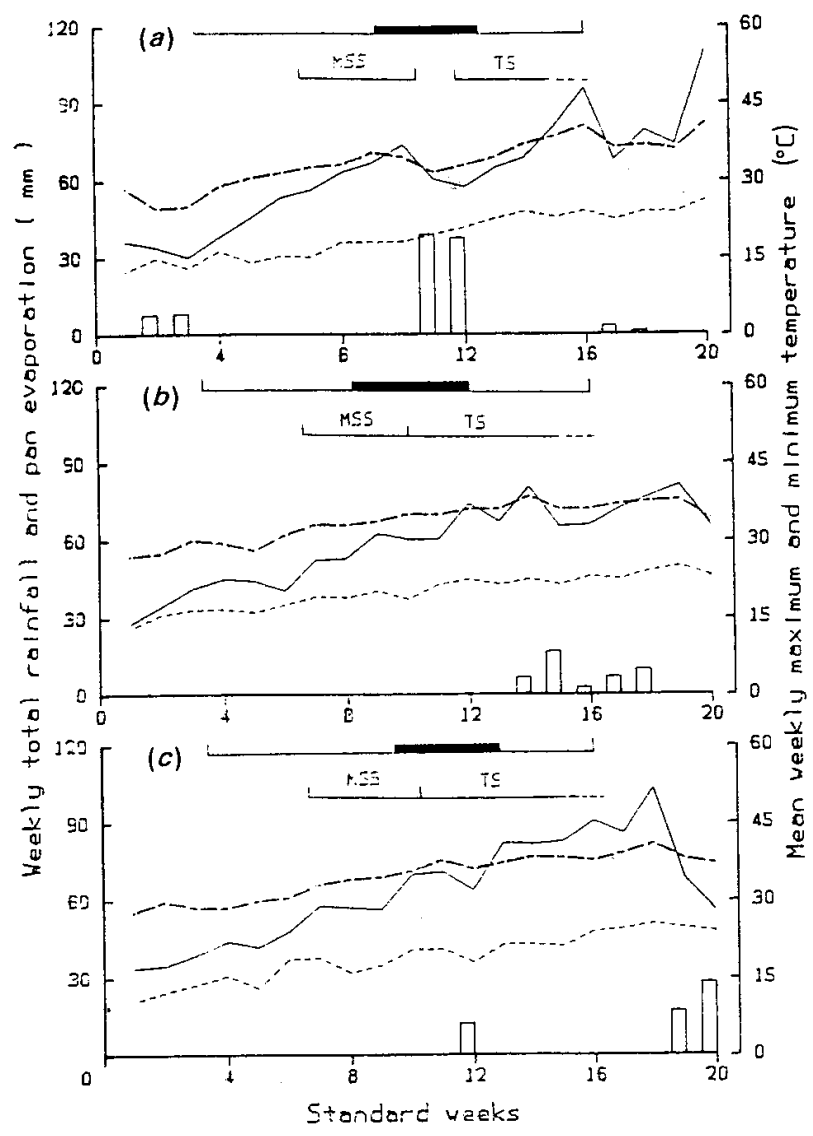

Fig. 1. Weekly mean values for maximum (-- - - ) and minimum (-- - ) temperatures and weekly total pan evaporation $(\longrightarrow$ ) and rainfall (bars). Crop development (irrigated control treatment) is indicated by the upper horizontal line where the beginning and end of the line indicate sowing and harvest and the bolder centre portion indicates the flowering period. The lower horizontal line represents the midseason stress (MSS) and terminal stress (TS) treatment periods. Data are for $1981(a), 1982(b)$ and 1983 (c).

\section{Crop Management}

All trials were sown by machine into dry soil on ridges $0.75 \mathrm{~m}$ apart and immediately furrowirrigated to fill the soil profile. All treatments were given a light sprinkler irrigation at 10-12 DAE, to rewet the upper $0.10 \mathrm{~m}$ of soil to allow adventitious root development, and thinned to a population of 13 plants per square metre. Following this, the midseason stress treatment received no further irrigation until approximately half of the entries in the control treatment had reached $50 \%$ flowering. The control and the terminal stress treatments received regular furrow irrigations from about 20 DAE, initially on a 10-day cycle, later in the season shortened to a 7-day cycle. In the terminal stress, irrigation was discontinued when the main shoot had reached $50 \%$ flowering in approximately one-half of the entries in the trial. (The delay in initiation of the terminal stress in 1981 was due to rain in weeks 11 and 12, Fig. 1). 
Nitrogen and phosphorus were banded in the ridges before planting at the rate of $40 \mathrm{~kg} \mathrm{~N}^{-1}$ and $18 \mathrm{~kg} \mathrm{Pha}^{-1}$, and a further $45 \mathrm{~kg} \mathrm{~N}^{-1}$ was topdressed following the sprinkler irrigation. Weeds were controlled by mechanical cultivation and hand weeding once on the ridges. Disease or pest control was not required.

\section{Design and Analysis}

The experiments were planted in a modified split-plot design with main plots (irrigation treatments) replicated twice, and subplots (entries) replicated twice within each main plot. Subplots were 4 rows $(3.0 \mathrm{~m})$ by $4.0 \mathrm{~m}$, of which 2 rows by $3.0 \mathrm{~m}\left(4.5 \mathrm{~m}^{2}\right)$ were harvested at maturity. Time to flowering was recorded when stigmas emerged in $50 \%$ of the main shoots in a plot. At harvest, data were taken on number of plants and panicles, on grain yield, and on 100 grain mass (from duplicate samples of 100 grains taken at random from the bulk plot harvest). These data were used to calculate number of grains per panicle and per unit area.

Although the identities of the three individual trials (hybrid, synthetic variety, and population variety trials) were maintained in the field, the majority of the analyses were done on the combined sets of 72 genotypes. Correlation analyses used genotype means, giving 70 d.f. Because grain numbers were estimated from grain yields and individual grain mass, correlations involving grain yield and grain number involved some element of autocorrelation.

Table 1. Mean yield and yield components in the three treatments for the advanced trials 1981,1982 and 1983

\begin{tabular}{|c|c|c|c|c|}
\hline & $\begin{array}{l}\text { Irrigated } \\
\text { control }\end{array}$ & $\begin{array}{c}\text { Midseason } \\
\text { stress }\end{array}$ & $\begin{array}{c}\text { Terminal } \\
\text { stress }\end{array}$ & s.e. ${ }^{A}$ \\
\hline \multicolumn{5}{|l|}{1981} \\
\hline Time to $50 \%$ flowering (days) & 55 & 63 & 55 & $0 \cdot 3$ \\
\hline Grain yield $\left(\mathrm{g} \mathrm{m}^{-2}\right)$ & 230 & 218 & 103 & $8 \cdot 7$ \\
\hline $10^{-3} \times$ grains $\left(\mathrm{m}^{-2}\right)$ & $36 \cdot 9$ & $35 \cdot 5$ & $21 \cdot 3$ & $1 \cdot 15$ \\
\hline Plants $\left(\mathrm{m}^{-2}\right)$ & $13 \cdot 8$ & $14 \cdot 5$ & $14 \cdot 3$ & $0 \cdot 17$ \\
\hline Panicles (plant ${ }^{-1}$ ) & $1 \cdot 9$ & $3 \cdot 1$ & $1 \cdot 3$ & 0.06 \\
\hline $10^{-3} \times$ grains (panicle ${ }^{-1}$ ) & $1 \cdot 45$ & $0 \cdot 83$ & $1 \cdot 17$ & $0 \cdot 084$ \\
\hline Individual grain mass (mg) & $6 \cdot 30$ & $6 \cdot 26$ & $4 \cdot 80$ & $0 \cdot 239$ \\
\hline \multicolumn{5}{|l|}{1982} \\
\hline Time to $50 \%$ flowering (days) & 44 & 47 & 43 & $0 \cdot 5$ \\
\hline Grain yield $\left(\mathrm{g} \mathrm{m}^{-2}\right)$ & 246 & 257 & 109 & $17 \cdot 0$ \\
\hline $10^{-3} \times$ grains $\left(\mathrm{m}^{-2}\right)$ & $37 \cdot 2$ & $40 \cdot 1$ & $24 \cdot 1$ & $2 \cdot 11$ \\
\hline Plants $\left(m^{-2}\right)$ & $12 \cdot 4$ & $11 \cdot 2$ & $12 \cdot 5$ & $0 \cdot 14$ \\
\hline Panicles (plant ${ }^{-1}$ ) & $1 \cdot 8$ & $3 \cdot 9$ & $1 \cdot 4$ & $0 \cdot 13$ \\
\hline $10^{-3} \times$ grains $\left(\right.$ panicle ${ }^{-1}$ ) & $1 \cdot 70$ & 0.98 & $1 \cdot 40$ & $0 \cdot 088$ \\
\hline Individual grain mass (mg) & $6 \cdot 70$ & $6 \cdot 40$ & $4 \cdot 44$ & $0 \cdot 291$ \\
\hline \multicolumn{5}{|l|}{1983} \\
\hline Time to $50 \%$ flowering (days) & 52 & 59 & 51 & $1 \cdot 9$ \\
\hline Grain yield $\left(\mathrm{g} \mathrm{m}^{-2}\right)$ & 298 & 249 & 97 & $21 \cdot 2$ \\
\hline $10^{-3} \times$ grains $\left(\mathrm{m}^{-2}\right)$ & $44 \cdot 8$ & $39 \cdot 4$ & $20 \cdot 9$ & $2 \cdot 19$ \\
\hline Plants $\left(\mathrm{m}^{-2}\right)$ & $11 \cdot 8$ & $9 \cdot 2$ & $11 \cdot 7$ & $0 \cdot 19$ \\
\hline Panicles (plant ${ }^{-1}$ ) & $2 \cdot 6$ & $3 \cdot 7$ & $1 \cdot 3$ & $0 \cdot 47$ \\
\hline $10^{-3} \times$ grains (panicle $e^{-1}$ ) & $1 \cdot 60$ & $1 \cdot 27$ & $1 \cdot 36$ & 0.071 \\
\hline Individual grain mass (mg) & $6 \cdot 73$ & $6 \cdot 35$ & $4 \cdot 54$ & $0 \cdot 191$ \\
\hline
\end{tabular}

A Standard error of difference for comparing treatment means.

\section{Results}

\section{Effects of the Stress Treatments}

Flowering in the midseason stress was delayed by approximately 6 days (Table $1)$, with an increasing delay in later-flowering genotypes. Grain yields in the 
midseason stress were similar to those in the irrigated control in 2 of the 3 years. Plant numbers were reduced to a slight degree in 1982 and to a greater degree in 1983, when there was 30-50\% mortality in some of the early-flowering genotypes. The number of panicles per plant increased markedly in the midseason stress treatment, as tillers which would not have reached flowering in the irrigated crop did so following the termination of the stress. The number of grains on these panicles was considerably less than on those in the irrigated crop however. Individual grain mass was little affected by stress, as grain filling in most entries did not begin until after the stress was relieved.

Flowering in the terminal stress was not affected as the main shoot reached flowering before the stress became severe (Fig. 1a-1c). Grain yields, however, were reduced by more than $50 \%$ in this treatment, and all yield components (except number of plants) were affected (Table 1). Reduction in grain number occurred through both a reduction in average number of grains produced per panicle and a failure of a significant percentage of the tillers to reach flowering or produce grain. The effect of the terminal stress on panicles per plant was similar to or greater than that on individual grain mass, despite the fact that the latter is the yield component to be determined last in the growth of the crop (Table 1).

\begin{tabular}{|c|c|c|c|}
\hline & 1981 & 1982 & 1983 \\
\hline \multicolumn{4}{|l|}{ Midseason stress yield to: } \\
\hline Yield potential (control) & $0 \cdot 27^{*}$ & -0.19 & $0 \cdot 50^{* * *}$ \\
\hline Time to flower (control) & $-0 \cdot 27^{*}$ & $0 \cdot 74$ & $0 \cdot 69 * * *$ \\
\hline \multicolumn{4}{|l|}{ Yield structure (stress) } \\
\hline Grains $m^{-2}$ & $0 \cdot 68 * * *$ & $0 \cdot 81 * * *$ & $0 \cdot 89^{* * *}$ \\
\hline Plants $m^{-2}$ & $0 \cdot 13$ & $0 \cdot 70^{* * *}$ & $0 \cdot 61^{* * *}$ \\
\hline Panicles plant ${ }^{-1}$ & $0 \cdot 33^{* *}$ & $-0 \cdot 68 * * *$ & $-0 \cdot 55^{* * *}$ \\
\hline Grains panicle ${ }^{-1}$ & $0 \cdot 15$ & $0 \cdot 75^{* * *}$ & $0 \cdot 78 * * *$ \\
\hline Individual grain mass & -0.05 & $0 \cdot 60^{* * *}$ & $0 \cdot 28^{* *}$ \\
\hline \multicolumn{4}{|l|}{ Terminal stress yield to: } \\
\hline Yield potential (control) & $0 \cdot 38 * *$ & $0 \cdot 29 *$ & 0.05 \\
\hline Time to flower (control) & $-0 \cdot 80^{* * *}$ & $-0 \cdot 65^{* * *}$ & $-0 \cdot 81 * * *$ \\
\hline \multicolumn{4}{|l|}{ Yield structure (stress) } \\
\hline Grains $m^{-2}$ & $0 \cdot 82 * * *$ & $0 \cdot 64^{* * *}$ & $0 \cdot 84^{* * *}$ \\
\hline Plants $m^{-2}$ & $0 \cdot 20$ & $0 \cdot 18$ & $-0 \cdot 14$ \\
\hline Panicles plant ${ }^{-1}$ & $0 \cdot 69 * * *$ & $0 \cdot 42 * * *$ & $0 \cdot 80^{* * *}$ \\
\hline Grains panicle $e^{-1}$ & $0 \cdot 29^{*}$ & 0.07 & 0.00 \\
\hline Individual grain mass & $0 \cdot 47 * * *$ & $0 \cdot 62^{* * *}$ & $0 \cdot 46 * * *$ \\
\hline
\end{tabular}

${ }^{* * *} P<0.001 ; * * 0.001<P<0.01 ; * 0.01<P<0.05$.

\section{Factors Affecting Grain Yield in the Stress Treatments}

Grain yield in the stress treatments was analysed in two ways: (1) correlation of yields under stress with the yields and time to flowering in the irrigated treatment, to test for the effects of yield potential and drought escape on yield under stress, and (2) correlation of the grain yield in the two stress environments with yield components, to determine if certain yield component patterns were more advantageous than others under stress (e.g. small grain mass in terminal stress). 
Irrigated control yield (yield potential) was significantly correlated to yield in the stress treatment in 2 or 3 years for each treatment (Table 2). The magnitude of this association was small, however, with no more than $25 \%$ of the variation in grain yield under drought attributable to differences in yield potential.

The effects of time of flowering in contrast were very strong in five of the six stress treatment and year combinations, explaining an average of 51\% (1982 and 1983 ) of the variation in yield in the midseason stress and $57 \%$ in the terminal stress treatments (Table 2). In contrast, the correlation of grain yield and time to flowering in the irrigated control treatment was significant only in 1981, and time to flowering explained on the average only $6 \%$ of the variation in grain yield (Table 3 ). In the terminal stress the early-flowering lines had the advantage in all 3 years, as expected (Fig. $2 b$ ). In the midseason stress there was a clear advantage to later flowering in 1982 and 1983 (Fig. 2a), but not in 1981.

Table 3. Correlations of time to flowering and yield components in the irrigated control treatment. Advanced trials 1981, 1982, and 1983

\begin{tabular}{lccc}
\hline & 1981 & 1982 & 1983 \\
\hline Grains m $^{-2}$ & $-0 \cdot 15$ & $0 \cdot 02$ & $0 \cdot 29^{*}$ \\
Plants m $^{-2}$ & $-0 \cdot 48^{* * *}$ & $-0 \cdot 03$ & $0 \cdot 12$ \\
Panicles plant $^{-1}$ & $-0 \cdot 72^{* * *}$ & $-0 \cdot 70^{* * *}$ & $-0 \cdot 56^{* * *}$ \\
Grains panicle $^{-1}$ & $0 \cdot 79^{* * *}$ & $0 \cdot 71^{* * *}$ & $0 \cdot 84^{* * *}$ \\
Individual grain mass $_{\text {Grain yield } \mathrm{m}^{-2}}$ & $-0 \cdot 17$ & $-0 \cdot 29^{*}$ & $-0 \cdot 34^{* *}$ \\
& $-0 \cdot 34^{* *}$ & $-0 \cdot 21$ & $-0 \cdot 11$ \\
\hline
\end{tabular}

${ }^{* * *} P<0.001 ; * * 0.001<P<0.01 ;{ }^{*} 0.01<P<0.05$.
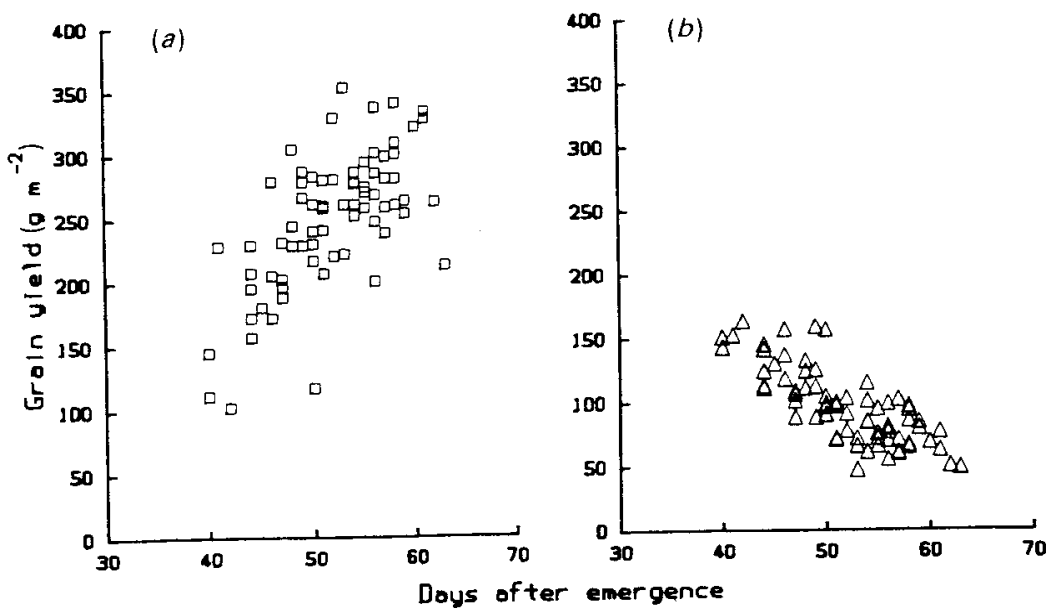

Fig. 2. (a) Relationship of grain yield and time to fiowering in the midseason stress treatment, 1983. Results from 1982 were similar. (b) Relationship of grain yield and time to flowering in the terminal stress treatment, 1983. Results from 1981 and 1982 were similar

In the analysis of yield components and grain yield, the number of grains per unit area was positively correlated to grain yield in all years in both stress treatments (Table 2), although the contribution of the components which make up number of grains per unit area varied with treatment. In the terminal stress yields 
were primarily associated with panicles per plant, rather than with either number of plants or number of grains per panicle. In the midseason stress, number of plants was an important determinant of yield in 1982 and 1983, where there was death of plants due to stress (Table 1). Also in these 2 years, there was a strong apparent advantage to a low number of panicles per plant and large panicles in the midseason stress (Table 2). However, this correlation appeared to be an artefact of the relationship between this phenotype and later flowering, which favored higher grain yields (Table 3 ).

Individual grain mass was associated with grain yield in the terminal stress in all 3 years, but to a lesser degree than grain number (Table 2). Grain mass in the midseason stress was less affected than in the terminal stress (Table 1), but the relationship to grain yield was still positive in 2 of the 3 years.

\section{Effects of Phenology}

The range in mean time to flowering among the entries was relatively broad in each year (mean of 21 days). It was larger than the range for the same entries grown at the same location in the rainy season without stress (mean of 13 days), although mean time to flowering was only 4 days greater in the dry than in the rainy season (50 v. 46 days, Pearl Millet Improvement Program, ICRISAT, unpublished data). This broader range in flowering did not appear to be the reason for the strong effects of time to flowering on yields under stress; these relationships, whether significant or not, did not appear to depend on the spread in flowering (Fig. 2).

Table 4. Correlations of time to flowering and yield components in the stress treatment, as a proportion of those in the irrigated control. Advanced trials 1981,1982 , and 1983

\begin{tabular}{|c|c|c|c|}
\hline & 1981 & 1982 & 1983 \\
\hline \multicolumn{4}{|l|}{ Midseason stress/control } \\
\hline Grains $m^{-2}$ & $-0 \cdot 44^{* * *}$ & $0 \cdot 51 * * *$ & $0 \cdot 51^{* * *}$ \\
\hline Plants $\mathrm{m}^{-2}$ & 0.05 & $0 \cdot 51 * * *$ & $0 \cdot 49 * * *$ \\
\hline Panicles plant ${ }^{-1}$ & $-0 \cdot 17$ & $-0 \cdot 11$ & $-0 \cdot 15$ \\
\hline Grains panicle $^{-1}$ & $-0 \cdot 23$ & $0 \cdot 40^{* * *}$ & $0 \cdot 04$ \\
\hline Individual grain mass & $0 \cdot 75^{* * *}$ & $0 \cdot 70^{* * *}$ & $0.66^{* *}$ \\
\hline Grain yield $\mathrm{m}^{-2}$ & $0 \cdot 04$ & $0 \cdot 69 * * *$ & $0 \cdot 73^{* * *}$ \\
\hline \multicolumn{4}{|l|}{ Terminal stress/control } \\
\hline Grains $m^{-2}$ & $-0 \cdot 64^{* * *}$ & $-0 \cdot 47 * * *$ & $-0 \cdot 76^{* * *}$ \\
\hline Plants $m^{-2}$ & $0 \cdot 15$ & $-0 \cdot 25^{*}$ & 0.09 \\
\hline Panicles plant ${ }^{-1}$ & -0.09 & $-0 \cdot 03$ & $-0 \cdot 32 * *$ \\
\hline Grains panicle $^{-1}$ & $-0 \cdot 66^{* * *}$ & $-0 \cdot 40^{* * *}$ & $-0 \cdot 77^{* * *}$ \\
\hline Individual grain mass & $-0 \cdot 42 * * *$ & $-0 \cdot 39^{* * *}$ & $-0 \cdot 38 * * *$ \\
\hline Grain yield $\mathrm{m}^{-2}$ & $-0 \cdot 70^{* * *}$ & $-0 \cdot 49 * * *$ & $-0 \cdot 80^{* * *}$ \\
\hline
\end{tabular}

***P<0.001; **0.001 $<P<0.01 ; * 0.01<P<0.05$.

There were strong correlations of time to flowering and two yield components in the irrigated control treatment - panicles per plant and grains per panicle (Table 3). Early-flowering lines consistently had a larger number of smaller panicles than the later-flowering lines; they also tended to have smaller individual grain size. These differences were compensatory, however, and time to flowering had little effect on either grains per unit area or on grain yield in the irrigated control. 
Relative (stress to irrigated control) values of grain yield and its components were calculated for the stress treatments, to eliminate the effects of differences in yield component structure among genotypes in the analysis of phenology effects on response to stress. These relative values were strongly affected by phenology in both stress treatments. In the midseason stress, the later-flowering lines were better able to maintain number of plants per unit area and thereby number of grains per unit area, than were the early lines in 1982 and 1983 (Table 4). In 1981 in contrast, there was a significant reduction in relative number of grains per unit area in the later lines. In all 3 years, the later-flowering lines were better able to maintain individual grain mass. In 1981 the opposing effects of time of flowering on grains per unit area and individual grain mass cancelled each other out, resulting in no advantage to early or late flowering, in the ability to maintain grain yield in the midseason stress. In the other 2 years, there was a strong advantage to later flowering in maintenance of grain yield, as the maintenance of both yield components was better in the later lines.

In the terminal stress in all years, early flowering was related to better maintenance of both individual grain mass and number of grains per unit area, and therefore to grain yield (Table 4). Differences in maintenance of number of grains per unit area were determined primarily by maintenance of number of grains per panicle, rather than by maintenance of number of panicles in this treatment.

\section{Discussion}

\section{Treatment Effects}

The responses of pearl millet to both stresses differed from those reported in wheat and barley (Day and Intalap 1970; Day et al. 1978; Innes and Blackwell 1981; Johnson and Kanemasu 1982; Innes et al. 1985). In the studies cited the major effect of a pre-anthesis (midseason) stress was a reduction in number of ears per unit area, with a secondary effect on number of grains per ear. A post-anthesis stress in contrast affected primarily individual grain size, with number of ears and grains per ear usually unaffected. In the present investigation with pearl millet, a pre-anthesis stress resulted in a large mean increase in number of panicles $(80 \%)$, with an associated decrease in mean number of grains per panicle $(35 \%)$ (Table 1 ). In the terminal stress the yield reduction was due to a decrease in number of panicles $(40 \%)$, with a secondary but significant decreases in individual grain mass $(30 \%)$ and number of grains per panicle $(20 \%)$ (Table 1$)$.

The differences in both stress treatments were probably associated with the extended periods of flowering in pearl millet, averaging 20-25 days (Mahalakshmi and Bidinger 1985), due to the asynchronous development of the tillers (Ramond 1968). Although the terminal stress began after the majority of individual plants had reached flowering, as judged by the main shoot, the asynchrony of flowering meant that there were many tillers which had not flowered. Under the severe stress imposed, these tillers are susceptible to a reduction in grain set or to complete failure to reach flowering, in addition to the expected reduction in the size of the grains filled (Mahalakshmi et al. 1987).

In the midseason stress, the asynchrony of tiller development resulted in shoots in a wide range of developmental stages during the stress, making possible a range of specific interactions with the stress. The most advanced shoots continue development, but suffer considerable reduction in grain number of grains per 
panicle and some reduction in grain size (Mahalakshmi and Bidinger 1985). Intermediate shoots reach floral initiation, but subsequent development is delayed, and flowering occurs only after the termination of the stress. In the very late shoots even floral initiation may be delayed until the stress is relieved.

In addition to delaying development, the midseason stress also resulted in a significant increase in the number of tillers producing a panicle. The panicles produced by these additional tillers are less productive than normally developing panicles, but they do make a significant contribution to grain yield (Mahalakshmi and Bidinger 1986), unlike wheat (Robbins and Domingo 1962) and barley (Day et al. 1978), where late tillers usually produce little or no grain.

It has been argued that both of these responses to drought - developmental plasticity and asynchrony of tiller development - should have value under intermittent drought conditions (Turner 1982), as appears to be the case in the midseason stress. Neither response, however, was of value in the terminal stress. A clear definition of the timing of occurrence of stress in a given environment is therefore necessary in assessing the value specific responses to drought.

\section{Phenology Effects}

Differences in developmental pattern can interact with drought stress in two different ways: by affecting yield component structure (Table 3), which in turn influences grain yield under stress; or by drought escape, which affects the degree to which a genotype is able to maintain the expression of a given yield component under stress, relative to its nonstressed value (Table 4). From the analysis of these two sets of relationships in these experiments, it appears that drought escape rather than an association of phenology and yield component structure was the basis for strong effects of phenology on grain yield (Table 2).

\section{Terminal stress}

In the terminal stress, time to flowering accounted for an average of $46 \%$ of the variation in relative yield (Table 4) and $57 \%$ of variation in absolute yield (Table 2), considerably higher than the $12-16 \%$ in wheat reported by Fischer and Wood (1979) for a similar range in time to flowering. The advantages of earliness in this type of stress have been documented in many other crops (e.g. Blum 1970; Fischer and Wood 1979; Innes et al. 1985).

Early-flowering genotypes were better able to maintain number of grains per panicle and thus per unit area in the terminal stress (Table 4). In comparable (severe) stress conditions in wheat, early flowering resulted in better maintenance of number of grains through maintenance of number of ears, rather than maintenance of number of grains per ear (Fischer and Wood 1979). The difference in the way in which a high number of grains per unit area in the two crops is achieved (primarily by number of ears per unit area in wheat and number of grains per panicle in millet) may explain the relatively greater sensitivity of number of ears in wheat and number of grains per panicle in millet. Under more moderate terminal stress conditions the benefit of early flowering in wheat was similar to that in millet, i.e. better maintenance of number of grains per ear (Innes et al. 1985).

Effects of early flowering on individual grain mass in the terminal stress were similar in millet (Table 4) and in wheat under moderate stress (Innes et al. 1985), but in contrast to the results of Fischer and Wood (1979) under severe stress. In 
the latter study individual grain mass in the terminal stress was positively correlated to later flowering, probably as a result of greater loss in number of grains in the later-flowering lines than in the ealier ones. Number of grains was reduced more in the later-flowering genotypes in the millet, but this did not result in any advantage in individual grain mass (Table 4).

\section{Midseason stress}

Later flowering in the midseason stress was advantageous in 2 of the 3 years, accounting for approximately $50 \%$ of the variation in both absolute (Table 2) and relative (Table 4) yields. A similar, but less marked, advantage to later flowering has been reported in wheat under pre-anthesis stress terminating both at flowering (Innes et al. 1985) and several weeks before flowering (Fischer et al. 1977). The advantage of late flowering in wheat in both cases was related to better maintenance of number of grains per unit area. Although this occurred in 2 of the 3 years in pearl millet, the greatest advantage to late flowering in millet in all three years was on individual grain mass (Table 4), which may have been related to the greater new leaf area development in the late lines following the rewatering of the stressed plots.

Although late flowering provided an effective escape to midseason stress, it would be expected to increase the risk of terminal stress in many millet-growing environments. This did not occur in these experiments (in which irrigation was continued until all genotypes reached maturity), but would need to be considered in natural stress environments.

The contrasting effects of time to flowering in the midseason and terminal stress treatments makes a clear definition of the timing of stress critical. This is true both in research on the effects of stress as well as in making recommendations to farmers on the choice of a variety in drought-prone environments. If probabilities of the occurrence of stress at different times in the crop cycle are not known, it is clearly not possible to utilize phenology to capitalize on the drought escape potential in the crop.

\section{Yield Components and Yield}

The relationships of grain yield and yield component structure measured in the two stress treatments (Table 2) seem to suggest that certain yield structures may be advantageous in each stress treatment. This has been shown clearly for wheat (Innes and Blackwell 1981; Innes et al. 1981), in which lines having a low number of ears and high grain yield per ear outyielded lines with the opposite yield structure during a pre-anthesis drought (when tiller number was affected), but were less successful during a post-anthesis drought (when grain yield per ear was most affected). In the present experiments, however, many of the correlations of yield in the stress and yield components appear to be a consequence of phenology and drought escape. The correlations between yield in the stress and number of panicles per plant (Table 2), for example, simply reflect the differences in number of panicles in the early and late-flowering genotypes (Table 3), and their relative advantages in each stress treatment. Against a background of strong phenological effects on yield component structure, correlation analyses of yield component-yield relationships under stress simply reflect the yield-phenology relationships under stress, and do not provide useful insights into yield differences. 


\section{Assessment of Drought Resistance}

Given the strong effects of phenology and the lesser but significant effects of yield potential on grain yields in the stress treatments in these experiments, it is clear that actual grain yield in the stress is of little value in describing a genotype's drought resistance, particularly where the latter is considered to be an independent genetic character. Nor will actual grain yields be of use in a black box analysis to identify traits associated with drought resistance where strong phenological effects exist.

Table 5. Percentage of the total variation in grain yield accounted for by the combined effects of variation in yield potential and time to flowering. Advanced trials 1981, 1982, and 1983

\begin{tabular}{lcc}
\hline Year & Midseason stress & Terminal stress \\
\hline 1981 & 26 & 65 \\
1982 & 67 & 44 \\
1983 & 80 & 66 \\
Mean & 58 & 58 \\
\hline
\end{tabular}

In fact, a regression analysis of the combined effects of phenology and yield potential on grain yields in the stress treatments indicated that these two factors accounted for more than half of the observed variation in grain yield in the stress (Table 5). We have found this in other data sets as well (Bidinger et al. 1982). Allowing for experimental error, it seems evident that differences in drought resistance (again defined as an independent trait) among genotypes were a secondary rather than the primary factor in the differences in genotype yields in the stress treatments in the genotypes evaluated in these experiments. The relationships in Table 5, however, do suggest that an estimate of genotype drought resistance, based on the unexplained or residual variation in grain yield in the stress after the effects of yield potential and time of flowering are accounted for, should provide a better basis for the black box analysis of genotype effects than does grain yield itself. Such an index is the subject of the following paper (Bidinger et al. 1987).

\section{References}

Bidinger, F. R., Mahalakshmi, V., and Rao, G. D. P. (1987). Assessment of drought resistance in pearl millet. II. Estimation of genotype response to stress. Aust. J. Agric. Res. 38, 49-59.

Bidinger, F. R., Mahalakshmi, V., Talukdar, B. S., and Alagarswamy, G. (1982). Improvement of drought resistance in pearl millet. In 'Drought Resistance in Crops With Emphasis on Rice'. pp. 357-76. (IRRI: Los Baños, Philippines.)

Blum, A. (1970). Effect of plant density and growth duration on grain sorghum yield under limited water supply. Agron. J. 62, 333-6.

Blum, A. (1979). Genetic Improvement of drought resistance in crop plants: a case for sorghum. In 'Stress Physiology in Crop Plants'. (Eds. H. Mussell and R. C. Staples.) pp. 430-45. (Wiley Interscience: New York.)

Day, A. D., and Intalap, S. (1970). Some effects of soil moisture stress on the growth of wheat. Agron. J. 62, 27-9.

Day, W., Legg, B. J., French, B. K., Johnston, A. F., Lawlor, D. W., and Jeffers, W. (1978). A drought experiment using mobile shelters: the effect of drought on barley yield, water use and nutrient uptake. J. Agric. Sci. 91, 599-623. 
Fischer, K. S., Johnson, E. C., and Edmeades, G. O. (1982). Breeding and selection for drought resistance in tropical Maize. In 'Drought Resistance in Crops with Emphasis on Rice'. pp. 337-400. (IRRI: Los Baños, Philippines.)

Fischer, R. A. (1981). Optimizing the use of water and nitrogen through breeding crops. Plant Soil. 58, 249-78.

Fischer, R. A., Lindt, J. H., and Glave, A. (1977). Irrigation of dwarf wheats in the Yaqui Valley of Mexico. Exp. Agric. 13, 353-69.

Fischer, R. A., and Maurer, R. (1978). Drought resistance in spring wheat cultivars. I. Grain yield response. Aust. J. Agric. Res. 29, 897-912.

Fischer, R. A., and Wood, J. T. (1979). Drought resistance in spring wheat cultivars. III. Yield associations with morphophysiological traits. Aust. J. Agric. Res. 30, 1000-20.

Hurd, E. A. (1969). A method of breeding for yield of wheat in semi-arid climates. Euphytica 18, 217-26.

Hurd, E. A. (1974). Phenotype and drought tolerance in wheat. Agric. Meterol. 14, 39-55.

Innes, P., and Blackwell, R. D. (1981). The effect of drought on the water use and yield of two spring wheat genotypes. J. Agric. Sci. 96, 603-10.

Innes, P., Blackwell, R. D., Austin, R. B., and Ford, M. A. (1981). The effects of selection for number of ears on the yield and water economy of winter wheat. J. Agric. Sci. 97, 523-32.

Innes, P., Hoogendorn, J., and Blackwell, R. D. (1985). Effect of differences in date of ear emergence and height on yield of winter wheat. J. Agric. Sci. 105, 543-9.

IRRI (1982). 'Drought Resistance in Crops with Emphasis on Rice.' (IRRI: Los Baños, Philippines.)

Johnson, R. C., and Kanemasu, E. T. (1982). The influence of water availability on winter wheat yields. Can. J. Plant. Sci. 62, 831-8.

Mahalakshmi, V., and Bidinger, F. R. (1985). Flowering response of pearl millet to water stress during panicle development. Ann. Appl. Biol. 106, 571-8.

Mahalakshmi, V., and Bidinger, F. R. (1986). Water deficit during panicle development in pearl millet: yield compensations by tillers. J. Agric. Sci. 106, 113-19.

Mahalakshmi, V., Bidinger, F. R., and Raju, D. S. (1986). Effect of timing of water stress in pearl millet [Pennisetum americanum (L.) Leeke]. Field Crops Res. (in press).

Quisenberry, J. E. (1982). Breeding for drought resistance and plant water use efficiency. In 'Breeding Plants for Less Favourable Environments'. (Eds. N. M. Christiansen and C. F. Lewis.) pp. 193-212. (Wiley Interscience: New York.)

Ramond, C. (1968). Pour une meilleure connaissance de la crossance et du development des mils Pennisetum. Agron. Trop. 8, 844-63.

Richards, R. A. (1982). Breeding and selecting for drought resistance in wheat. In 'Drought Resistance in Crop Plants with Emphasis on Rice'. pp. 303-16. (IRRI: Los Baños, Philippines.)

Robbins, J. S., and Domingo, C. E. (1962). Moisture and nitrogen effects on irrigated spring wheat. Agron. J. 54, 135-8.

Simpson, G. M. (1981). The value of physiological knowledge of water stress in plants. In 'Water Stress on Plants'. (Ed. G. M. Simpson.) pp. 235-65. (Praeger: New York.)

Turner, N. C. (1982). The role of shoot characteristics in drought resistance of crop plants. In 'Drought Resistance in Crops with Emphasis on Rice'. pp. 115-34. (IRRI: Los Baños, Philippines.)

Manuscript received 14 March 1986, accepted 8 August 1986 